\title{
Fotovoltaik Panel ve Şebeke Entegrasyonlu Akıllı Sokak Lambası Tasarımı ve Uygulaması
}

\author{
Ömür Akyazi ${ }^{1 *}$, Erdinç Şahin ${ }^{2}$, Doğan Can Kahveci ${ }^{3}$ \\ ${ }^{1}$ Karadeniz Teknik Üniversitesi, Of Teknoloji Fakültesi, Enerji Sistemleri Mühendisliği Bölümü, Trabzon, Türkiye (ORCID: 0000-0001-6266-2323) \\ ${ }^{2}$ Karadeniz Teknik Üniversitesi, Of Teknoloji Fakültesi, Enerji Sistemleri Mühendisliği Bölümü, Trabzon, Türkiye (ORCID: 0000-0002-9740-599X) \\ ${ }^{3}$ Karadeniz Teknik Üniversitesi, Of Teknoloji Fakültesi, Enerji Sistemleri Mühendisliği Bölümü, Trabzon, Türkiye
}

(This publication has been presented orally at HORA congress.)

(First received 1 August 2019 and in final form 25 October 2019)

(DOI: $10.31590 /$ ejosat.638314)

ATIF/REFERENCE: Akyazı, Ö., Şahin, E. \& Kahveci, D. C. (2019). Fotovoltaik Panel ve Şebeke Entegrasyonlu Akıllı Sokak Lambası Tasarımı ve Uygulaması. European Journal of Science and Technology, (Özel Say1), 356-360.

$\ddot{O} \mathbf{z}$

Enerjinin yaklaşık \%80'lik kısmının fosil yakıtlarından karşılandığı dünyamızda, enerji ülkeler için stratejik bir öneme sahiptir. Enerji ülkelerin gelişmişlik düzeylerini, uluslararası ilişkileri ve yaşam kalitesini belirleyen en önemli parametrelerden birisidir. Ülkemiz enerji bakımından dışa bağımlı olup bu bağımlılık ekonomik ve politik riskleri beraberinde getirmektedir. Bu bakımdan ülkemiz için üretilen enerjinin verimli kullanılması, yenilenebilir enerji kaynaklarına yönenilmesi ve enerjinin tüketilmesinde akılcı yolları kullanılarak tasarruf edilmesi önem arz etmektedir. Güneş enerjisinden yararlanarak enerjinin çok tüketildiği alanlardan biri olan aydınlatma sistemlerinde Akıllı ve LED'li aydınlatma konusu üzerine yapılan çalışmalar artmıştır. Bu çalışmada şebeke ile tümleşik PV panel kullanılarak akıllı sokak aydınlatması tasarlanmış ve uygulaması gerçekleştirilmiştir. Gerçekleştirilen sistemde gündüz PV panel vasıtasıyla güneşten elde edilen enerji led'li sokak lambasında kullanılmak üzere aküde depolanmaktadır. Led'li sokak lambasının ışık şiddeti araç veya yaya trafiğine göre değişmektedir. Ayrıca aküde depolanan enerjinin belirlenen seviyenin altına düşmesi durumunda şebeke üzerinde takviye edilerek sistemin kesintisiz enerjilendirilmesi sağlanmıştır. Sistem denetimi Arduino üzerinden gerçekleştirilmiş olup sistem için gerekli olan yazılımsal ve donanımsal aygıtlar başarılı bir şekilde tasarlanmıştır.

Anahtar Kelimeler: Akıllı sokak lambası, Güneş enerjisi, Yüksek Güçlü LED, Enerji verimliliği, Arduino.

\section{Smart Street Lamp Design and Application with PV Panel and Grid Integration}

\begin{abstract}
Energy, approximately $\% 80$ part is supplied from fossil fuels, has a strategic importance for countries. Also, it is one of the most critical parameters determining the development levels, international relations and quality of life of the countries. Our country is highly dependent on foreign countries in terms of energy and this dependency causes economic and political risks. In this respect, it is important to use produced energy efficiently, to manage renewable energy sources and to reduce energy consuming for our country. Studies on smart and LED lighting subjects have increased in the lighting systems which is one of the areas which solar energy is highly preferred. In this study, an intelligent street lighting system is designed and energized by PV integrated grid. In the realized system, the energy obtained from the sun through the PV panel is stored in a battery during the day and used for system lately. The light intensity of the LED street lamp varies depending on vehicle or pedestrian traffic. In addition, if the energy stored in the battery falls below the specified
\end{abstract}

* Corresponding Author: Karadeniz Teknik Üniversitesi, Of Teknoloji Fakültesi, Enerji Sistemleri Mühendsiliği Bölümü, Trabzon, Türkiye, ORCID: 0000-0001-6266-2323, oakyazi@,ktu.edu.tr 
level, energy demand of the system is supplied by grid uninterruptedly. Designed system is controlled via Arduino card and the required software and hardware devices are designed succesfully.

Keywords : Smart Street Lamp, Solar energy, High power LED, Energy efficiency, Arduino.

\section{Giriş}

Günümüz dünyasında nüfus artışı, sanayileşme ve teknolojik gelişmeler paralel olarak enerjiye olan talep hızlı bir artış göstermektedir[1, 2]. Enerjideki bu hızlı artışa rağmen dünya enerji ihtiyacının karşılanmasında fosil kaynaklar birincil enerji kaynağı olarak tartışmasız üstünlüklerini korumaktadır [3,4]. Dünyada fosil enerji kaynaklarının rezervlerinin belirli bölgelerde ve sınırlı olması, ciddi çevre sorunlarına yol açması [5], ülkeler için siyasi ve ekonomik sorunların oluşmasına neden olması gibi sebeplerden dolayı yenilenebilir enerji kaynaklarına olan ilgiyi artırmıştır[6-8]. Özellikle gelişmiş ülkeler yenilenebilir enerji kaynaklarından maksimum şekilde yararlanmaktadır. Enerji üretiminin büyük bir kısmı dışa bağımlı olan ülkemizde artan nüfus, gelişen sanayi ve büyüyen ekonomiye paralel olarak enerjiye olan talep hızlı bir artış göstermektedir [7]. Türkiye'nin artan enerji ihtiyacının karşılanması ve enerjide dışa bağımlılığın azaltılması için enerji kaynaklarının etkin kullanımı, yenilenebilir enerji kaynaklarına yönenilmesi, enerjinin yönetilmesi ve verimli kullanılması gibi bir takım unsurlar oldukça önem arz etmektedir. Bu bakımdan ülkemizde elektrik tüketiminin fazla olduğu aydınlatma alanında LED'li lamba kullanmak ve güneş enerjisi gibi yenilenebilir enerji kaynaklarına yönelerek enerji tasarrufu sağlanabilir [7].

Bu çalışma ile enerji kaybı ve maliyet gibi problemlerin olduğu karayollarındaki aydınlatma işlemlerine bir çözüm getirilmek istenmiş̧tir. Karayolları aydınlatmalarında kullanılan armatürler, led armatürlere göre daha pahalı olmasına rağmen kaliteli bir aydınlatma sağlamamaktadır. Bununla beraber tükettiği enerji konvansiyonel enerji kaynak tabanlı olduğu için enerjinin üretim ve tüketimi sınırlı olarak kontrol edilebilmektedir. Şebeke ile birleşik PV panel kullanılarak üretim ve tüketim arasındaki dengenin oluşturulması, enerji ihtiyacının yerinde karşılanarak iletim kayıplarının minimuma çekilmesi ve yenilenebilir enerjinin kullanımı artırılarak enerji tasarrufu sağlanmıştır. Ayrıca şebekedeki konvansiyonel enerjinin tüketimi azaltılarak belirlenen parametrelere göre aydınlatmanın kontrol edilmesi mümkün kılınmıştır [9].

Klasik yüksek basınçlı sodyum armatür ile led armatür kıyaslanacak olursa, rutin çalışma saatlerinde ve sabit güç tüketimi için yüksek basınçlı armatür kayıplar dâhil 175W, led armatür grubu ise yine kayıplar dâhil maksimum $90 \mathrm{~W}$ tüketmektedir. Ülkemizdeki farklı yol sınıflarında farklı değerlerde tüketim mevcuttur. Tablo 1'de sodyum armatürler ile led armatür karşılaştırılması ve Tablo2'de enerji kazanımları verilmiştir.

Table 1. Konvansiyonel Led Karşılaştırlması

\begin{tabular}{c|c|c|c|c}
\cline { 2 - 5 } & $\begin{array}{c}\text { YB Sodyum } \\
\text { Armatür } \\
\text { Tüketim }\end{array}$ & $\begin{array}{c}\text { Led Armatür } \\
\text { Tüketim }\end{array}$ & $\begin{array}{c}\text { Tüketim } \\
\text { Fark1 }\end{array}$ & $\begin{array}{c}\text { Tasarruf } \\
\text { Oranı }\end{array}$ \\
\hline Yol Sinifi-1 & $175 \mathrm{~W}$ & $90 \mathrm{~W}$ & $85 \mathrm{~W}$ & $\% 50$ \\
\hline Yol Sinifi-2 & $120 \mathrm{~W}$ & $58 \mathrm{~W}$ & $62 \mathrm{~W}$ & $\% 51,6$ \\
\hline
\end{tabular}

Table 2. Enerji Kazanımı ve Tasarruf Sonuçları

\begin{tabular}{c|c|c|c|c}
\cline { 2 - 5 } & $\begin{array}{c}\text { Tüketim } \\
\text { Fark1 }\end{array}$ & $\begin{array}{c}\text { Günlük } \\
\text { Kazanç }\end{array}$ & $\begin{array}{c}\text { Yıllık } \\
\text { Kazanç }\end{array}$ & $\begin{array}{c}\text { Yıllık } \\
\text { Tasarruf }\end{array}$ \\
\hline Yol Sinıf $\mathrm{l}-1$ & $85 \mathrm{~W}$ & $680 \mathrm{Wh}$ & $248,2 \mathrm{kWh}$ & $89,35 \mathrm{TL}$ \\
\hline Yol Sinıf $\mathrm{l}-2$ & $62 \mathrm{~W}$ & $496 \mathrm{Wh}$ & $181,04 \mathrm{kWh}$ & $65,17 \mathrm{TL}$ \\
\hline
\end{tabular}

Tablolardan da görüleceği üzere yıllık bazda tüketim bedeli ile yıllık bazda tasarruf bedeli verilmiştir. İşlemler yapılırken güncel kWh enerji tüketim bedeli 0,36 TL olarak alınmış ve günlük 8 saat çalıştığı kabul edilmiştir.

\section{Sistem Tasarımı}

Bu çalışmada şebeke ile tümleşik PV panel kullanılarak akıllı sokak aydınlatması tasarlanmış ve uygulaması gerçekleştirilmiştir. Gerçekleştirilen sistemde gündüz PV panel vasıtasıyla güneşten elde edilen enerji led'li sokak lambasında kullanılmak üzere aküde depolanmaktadır. Led'li sokak lambasının ışık şiddeti araç veya yaya trafiğine göre değişmektedir. Ayrıca aküde depolanan enerjinin belirlenen seviyenin altına düşmesi durumunda şebeke üzerinde takviye edilerek sistemin kesintisiz enerjilendirilmesi sağlanmıştır. 
Sistem denetimi Arduino üzerinden gerçekleştirilmiş olup sistem için gerekli olan yazılımsal ve donanımsal aygıtlar tasarlanmıştır. Sistemde kullanılan malzemeler Tablo 3'de verilmiştir.

Table 3. Sistemde tasarımında kullanılan malzemeler

\begin{tabular}{l|c|c|c}
\cline { 2 - 4 } & Gerilim (V) & Akım (A) & Güç (W) \\
\hline Monokristal PV Panel & 17,6 & 3,5 & 60 \\
\hline PWM Şarj Regülatörü & 12 & 10 & 120 \\
\hline Batarya & 12 & 7 & 84 \\
\hline Doğrultucu & 15 & 3 & 75 \\
\hline Led Armatür (x10) & 12 & 0,83 & 100 \\
\hline
\end{tabular}

Led armatürler her biri 1200 Lümen parlaklık değerine sahip ve \%100 parlaklıkta 12000 lümen aydınlatma yapabilecek kapasitede seçilmiştir. PV panelin güneşlenme süresine bağlı olarak Trabzon ili Of ilçesinde günlük 6 saat enerji üretebileceği ve havanın kararması ile yaklaşık 8 saat aydınlatma sağlayacağı varsayılmıştır. Akü gerilimi $10,5 \mathrm{~V}$ değerine düştüğünde şebeke devreye alınarak yükseltilecek ve akü dolduğunda otomatik olarak solar şarj regülatörü üzerinden bağlantısı kesilecektir. Led armatür grubunun parlaklık değerleri normal aydınlatmada birinci parlaklık konumda iken, PIR sensörü hareket algılandığı sürece ikinci parlaklık konumda ortamı aydınlatacaktır. 8 saat aydınlatma için gereken minimum güç $0,4 \mathrm{kWh}$, maksimum güç ise $0,8 \mathrm{kWh}$ olacaktır. Güneşin olduğu sürece 5 saat PV panelin enerji üretmesi ile 1 saat şebeke takviyesi gece boyu minimum aydınlatma ihtiyacını karşılamaktadır. Gerçekleştirilen sistemin blok yapısı ve sistem modeli Şekil 1 ve 2'de görülmektedir.

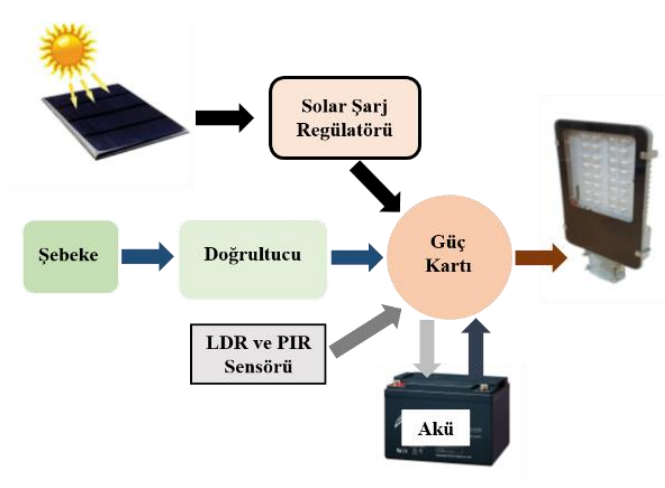

Şekil 1. Sistem blok şeması gösterimi

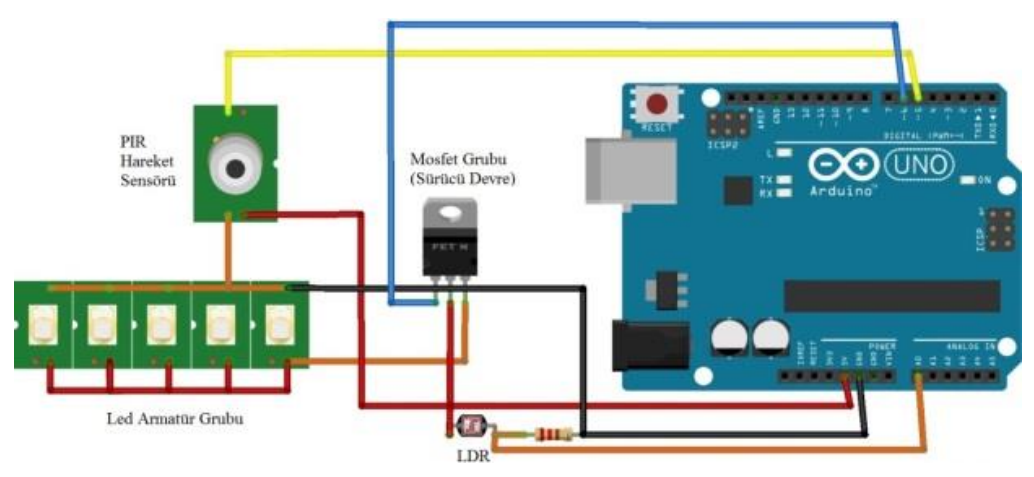

Şekil 2. Sistemin teknik çizim gösterimi

PV panel yardımıyla güneşten elde edilen enerji solar şarj regülatörü ve güç kartı üzerinden aküde depolanmaktadır. Solar şarj regülatörü güneşin durumuna veya konumuna bağlı olarak PV panelin üretmiş olduğu gerilimi belirli bir değerde sabitleyerek güç kartı üzerinden aküye iletmektedir. Güç kartı şebekenin, güneş enerjisinin, sensörlerin, akünün ve yükün belirlenen akış diyağramına göre çalışmasını sağlayan sistemin beyni konumundaki kısımdır. Sistemde kullanılan PIR sensörü hareketi algıladığı zaman çıkış vererek led armatürün parlaklığını kontrol etmektedir. LDR ise PV panel ile şebeke çalışma arasındaki geçişi sağlayacaktır. LDR çalışma prensibi gereği üzerine 1şık düştüğünde direnci düşer ve akım akışına izin verir. Ters durumda ise kesime götürür. Güneş'in olduğu durumda LDR üzerinden akım geçişine izin vereceğinden sistemin PV panel ile çalışmasına müsaade edecek, Güneş olmadığında ise şebekeye bağlantısına izin vererek yükün kesintisiz beslenmesi için akışın sağlanmasına yardımcı olacaktır.

Arduino üzerinde bulunan 2 adet analog pin, PIR sensörü ile LDR yi temsil etmektedir. Alınan bilgiler Şekil 3 ’te verilen Arduino kod akış diyagramındaki düzende işlenir. Bu bilgiler ile güç kartı birimi aracılığıyla batarya ile yük arasındaki akım ve gerilim kontrolü sağlanmaktadır. Şekil 3’te görüldüğü üzere batarya gerilimi 10,5V seviyesine düştüğü anda röle üzerinden şebekeye bağlantısı olacak şekilde tekrardan sensörü okuyarak işleme devam edecektir. PIR sensörü hareketi algılama parametresi ise analog olarak 500 sayısı referans değeridir. Sensör 500 değerinden düşük olarak algıladığı hareket için led grubunun \%50 parlaklık ile yanmasına, 500 değerinden yüksek olarak algıladı̆̆ hareket olursa led grubunun \%100 parlaklıkla yanmasına izin verecektir. Akışta bulunan gecikme ibaresi ise hareketin süresi ve sıklığına göre belirlenen ortalama bir aydınlatma süresidir. Şekil 4'te sistemin proteus çizimi verilmiştir.

Güç kartı üzerinde bulunan mosfetin kapı ucundan alınmış osiloskop görüntüsü ve akım-gerilim değerleri Şekil 5’te görülmektedir. Bu PIR sensörünün kesimde ve led grubunun birinci parlaklıkla yandığı zamana karşlık gelen durumdur. Anahtarlama eleman1 \%27.2 doluluk ile tetiklenmektedir. PIR sensörünün aktif ve led grubunun ikinci parlaklık durumunda tetikleme elemanının gate ucundan 


\section{European Journal of Science and Technology}

alınmış osiloskop görüntüsü ve akım-gerilim değerleri Şekil 6'da verilmiştir. Bu esnada anahtarlama elemanı \%69.9 doluluk oranı ile tetiklenmektedir. Şekil 7'de gerçekleştirilen sistemin genel görünümü verilmiştir.

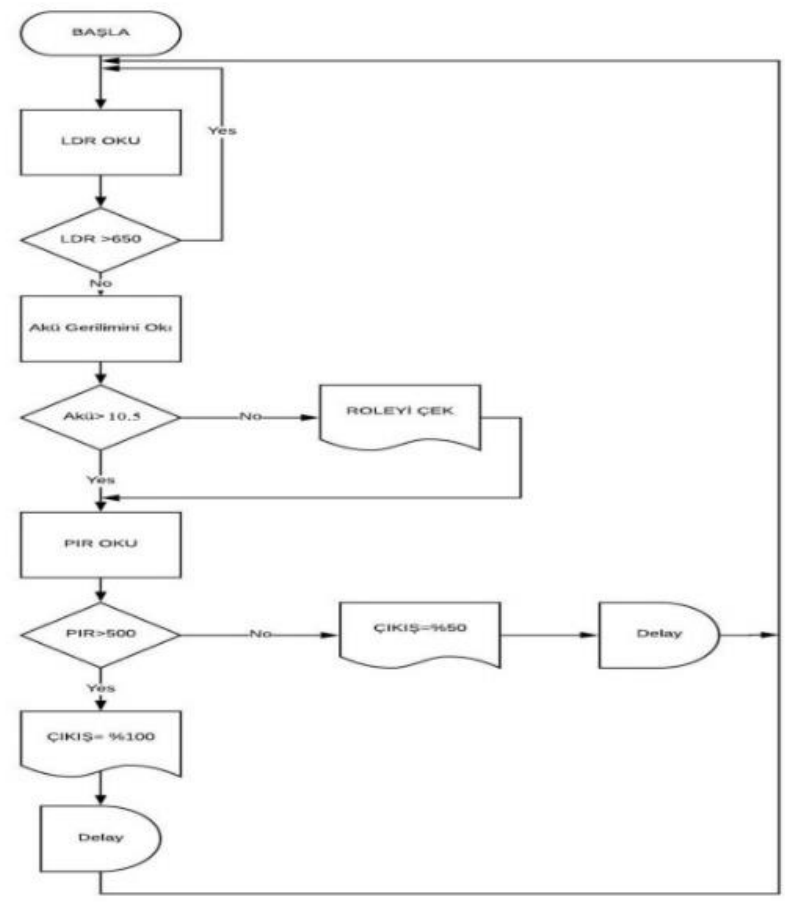

Şekil 3. Kod akış diyagramı

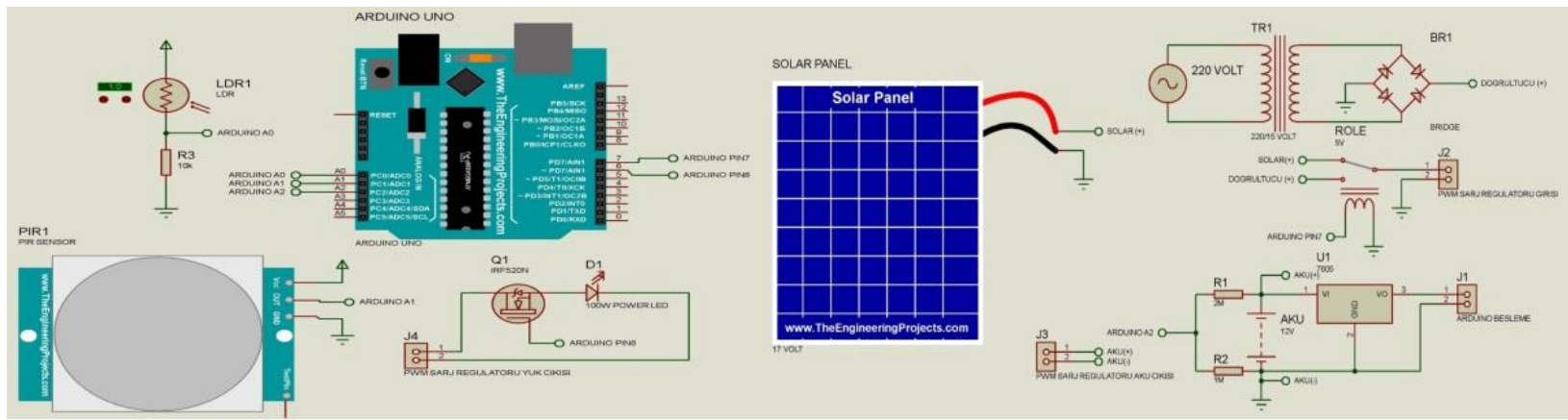

Şekil 4. Tasarlanan sistemin Proteus devre çizimi

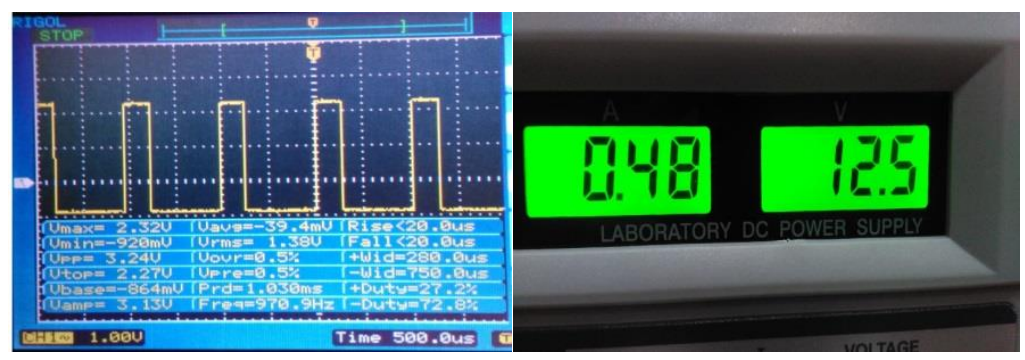

Şekil 5.Osiloskop Görüntüsü ve Akım-Gerilim Değerleri (PIR sensörü kesimde)

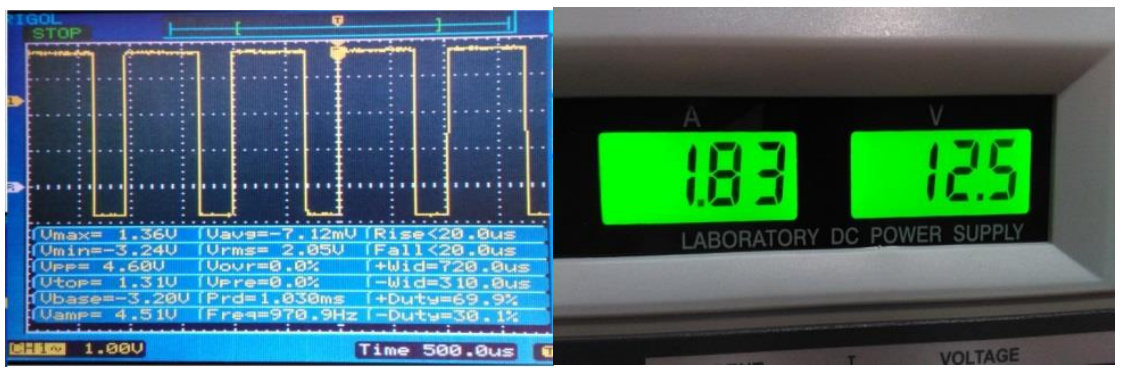


Şekil 6.Osiloskop Görüntüsü ve Akım-Gerilim Değerleri(PIR sensörü aktif)
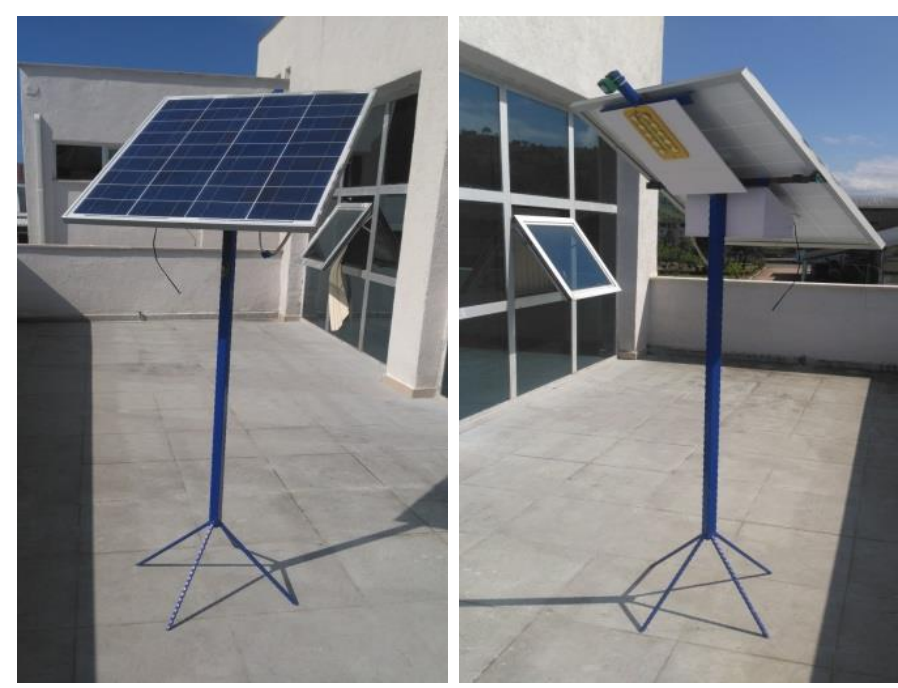

Şekil 7. Gerçekleştirilen sistemin ön ve arka fotoğrafları

\section{Sonuçlar ve Öneriler}

$\mathrm{Bu}$ çalışmada şebeke ile entegreli, güneş enerjisi ile şarj edilebilen akü sistemi üzerinden beslenen akıllı LED’li aydınlatma armatürü tasarlanmış ve uygulaması gerçekleştirilmiştir. Yapılan deneysel çalışmalarda LED'li aydınlatma armatürünün 1şık şiddeti yaya veya araç trafiğine bağlı olarak değişmekte olup sürekli aynı şiddette yanmayarak enerji tasarrufu sağladığı ve kullanılabilir olduğu görülmüştür. Ayrıca güneş enerjisinin yetersiz olduğu durumlarda LED'li aydınlatma armatürünün enerjisiz kalmaması ve dolayısıyla yaya veya araç trafiğinin konforunun azalmaması için mevcut enerji şebekesinden faydalanarak sistemin kesintisiz enerjilendirilmesi sağlanmıştır. Uygulaması gerçekleştirilen sistemin kontrolü Arduino geliştirme kartı üzerinden gerçekleştirilmiş olup sistem için gerekli olan yazılımsal ve donanımsal aygıtlar tasarlanmıştır.

PV paneller yardımıyla güneş enerjisinden elde edilen enerji akülerde depolanarak LED’li aydınlatma uygulamalarında kullanılması enerji tasarrufunu, güç kayıplarını azaltmayı ve şebeke geriliminin olmadığı yerlerde sokak veya cadde aydınlatmalarında kullanılmasına imkân sağlar. Ayrıca sistem üzerine yerleştirilecek kamera ile sokakların veya trafiğin denetimi sağlanabilir. Başlangıçta sistemin ilk kuruluş maliyeti yüksek olsa bile kendini kısa sürede amorti etme kabiliyetine sahiptir. Ayrıca ülkemizin ekonomik kalkınmasına ve enerji giderlerinin azaltılması için yenilenebilir enerjiye yönelerek aydınlatmada Led'li armatürlerin akıllı çözümlerle uygulana bilirliğinin yüksek olduğu görülmüştür.

\section{References}

[1] Richards, M., \& Carter, D. (2009). Good lighting with less energy: Where next?. Lighting Research and Technology, 41(3), 285.

[2] De Paz, J. F., Bajo, J., Rodríguez, S., Villarrubia, G., \& Corchado, J. M. (2016). Intelligent system for lighting control in smart cities. Information Sciences, 372, 241-255.

[3] Filimonova, A. A., Barbasova, T. A., \& Shnayder, D. A. (2017). Outdoor lighting system upgrading based on Smart Grid concept. Energy Procedia, 111, 678-688.

[4] Rajab, Z., Khalil, A., Amhamed, M., \& Asheibi, A. (2017, March). Economic feasibility of solar powered street lighting system in Libya. In 2017 8th International Renewable Energy Congress (IREC) (pp. 1-6). IEEE.

[5] Özçelik, M. A. (2017). The design and implementation of PV-based intelligent distributed sensor LED lighting in daylight exposed room environment. Sustainable Computing: Informatics and Systems, 13, 61-69.

[6] Masoud, M. I. (2015, February). Street lighting using solar powered led light technology: Sultan qaboos university case study. In 2015 IEEE 8th GCC Conference \& Exhibition (pp. 1-6). IEEE

[7] ÇOLAK, İ., İbrahim, S. E. F. A., BAYINDIR, R., \& DEMİRTAŞ, M. (2007). Güneş Enerjisi Kaynaklı LED Armatür Tasarımı. Politeknik Dergisi, 10(4), 347-352.

[8] Popović-Gerber, J., Ferreira, J. A., \& van Wyk, J. D. (2011). Quantifying the value of power electronics in sustainable electrical energy systems. IEEE Transactions on Power Electronics, 26(12), 3534-3544.

[9] Barra, K., \& Rahem, D. (2014). Predictive direct power control for photovoltaic grid connected system: An approach based on multilevel converters. Energy Conversion and Management, 78, 825-834. 